\title{
common mental disorders, neighbourhood income inequality and income deprivation: small-area multilevel analysis
}

\author{
David Fone, Giles Greene, Daniel Farewell, James White, Mark Kelly and Frank Dunstan
}

\section{Background}

Common mental disorders are more prevalent in areas of high neighbourhood socioeconomic deprivation but whether the prevalence varies with neighbourhood income inequality is not known.

\section{Aims \\ To investigate the hypothesis that the interaction between small-area income deprivation and income inequality was} associated with individual mental health.

\section{Method}

Multilevel analysis of population data from the Welsh Health Survey, 2003/04-2010. A total of 88623 respondents aged 18-74 years were nested within 50587 households within 1887 lower super output areas (neighbourhoods) and 22 unitary authorities (regions), linked to the Gini coefficient (income inequality) and the per cent of households living in poverty (income deprivation). Mental health was measured using the Mental Health Inventory MHI-5 as a discrete variable and as a 'case' of common mental disorder.

\section{Results}

High neighbourhood income inequality was associated with better mental health in low-deprivation neighbourhoods after adjusting for individual and household risk factors (parameter estimate +0.70 (s.e. $=0.33$ ), $P=0.036$; odds ratio (OR) for common mental disorder case 0.92 , $95 \% \mathrm{Cl} \mathrm{0.88-0.97).} \mathrm{Income} \mathrm{inequality} \mathrm{at} \mathrm{regional} \mathrm{level}$ was significantly associated with poorer mental health (parameter estimate -1.35 (s.e. $=0.54$ ), $P=0.012 ; \mathrm{OR}=1.13$, $95 \% \mathrm{Cl} 1.04-1.22)$

\section{Conclusions}

The associations between common mental disorders, income inequality and income deprivation are complex. Income inequality at neighbourhood level is less important than income deprivation as a risk factor for common mental disorders. The adverse effect of income inequality starts to operate at the larger regional level.

\section{Declaration of interest}

None.
Income inequality refers to how unequal the distribution of incomes is across a society. ${ }^{1}$ A large body of research has consistently demonstrated associations between income inequality at country-level and a range of adverse health outcomes, ${ }^{2}$ including poor mental health. An ecological study of aggregated data from 12 high-income countries found a strong linear association between income inequality and the prevalence of any mental illness (correlation coefficient $+0.79, P=0.002) .{ }^{3,4}$ In this analysis, the UK was eleventh worst on both measures, with the USA in twelfth place. In contrast, there is inconsistent evidence for an association between income inequality measured at subnational level and mental health outcomes. Studies have included economic areas, counties and community districts in the USA, ${ }^{5-7}$ British regions ${ }^{8}$ and neighbourhoods in The Netherlands. ${ }^{9}$ Of these five studies, three found no significant association between income inequality and mental health. ${ }^{5,6,9}$ Two studies did find a significant association, measuring income inequality for large community districts in New York City $(n=59)$ and depression consistent with DSM-IV criteria ${ }^{7}$ and for British regions with common mental disorder assessed by the General Health Questionnaire. ${ }^{8}$ One possible explanation for the contrast between subnational findings and country-level studies is that it has been theorised that income inequality is an inappropriate measure at subnational level, arguing that it is not within-area inequalities that are important but the comparison to the wider society. ${ }^{2,4}$ At smaller area-levels, the degree of inequality becomes smaller, and the differences between areas become larger, so that absolute levels of income and associated social and material disadvantage become a more important predictor of health outcomes. ${ }^{2}$ Some evidence for this is suggested by studies that have shown that area socioeconomic deprivation, a measure of comparative disadvantage, is associated with a higher prevalence of common mental disorders at both neighbourhood level in several countries ${ }^{10-13}$ and at regional level in Wales. ${ }^{14}$ However, it is not known whether income deprivation acts alone or interacts with income inequality as a social determinant of mental health. In this study we investigated the hypothesis that the interaction between small-area income deprivation and income inequality was associated with individual mental health by assessing multilevel associations with small-area measures of income inequality and income deprivation using a large population survey data-set.

\section{Method}

\section{Data source}

We analysed data from the seven available consecutive waves of the Welsh Health Survey 2003/04-2010, an annual cross-sectional survey of the resident adult population of Wales, described elsewhere. ${ }^{15,16}$ Briefly, a random sample of private households from the Postcode Address File is selected each year using a multistage probability sampling design with stratification. Data are collected from around 15000 adults, using a household interview and self-completion questionnaires by all adults in the household. The survey includes questions on a wide range of demographic, socioeconomic and health and lifestyle factors.

The data-set includes codes for the 2001 census geography of the 1896 lower super output areas (LSOA) ${ }^{17}$ and the 22 unitary authorities in Wales. The LSOAs are constructed to have a minimum population size of around 1000 and in Wales the mean population was 1558 (range 965-4161, IQR =1385-1682). We used the LSOA as a small-area proxy for 'neighbourhood'. 


\section{Mental health outcome measure}

We used the Mental Health Inventory (MHI-5) subscale of the 36-item Short Form Health Survey (SF-36) version 2 as the measure of common mental disorders. ${ }^{18}$ The MHI- 5 has been shown to be a robust measure of mental well-being in the general population, ${ }^{19}$ with close agreement with the 12 -item General Health Questionnaire (GHQ-12), ${ }^{20-22}$ and effective at screening for mood disorders and anxiety disorders, but not phobias, assessed using the Composite International Diagnostic Interview. $^{23,24}$

The MHI- 5 scale comprises five questions: in the past 4 weeks: (a) have you been very nervous? (b) have you felt so down in the dumps that nothing could cheer you up? (c) have you felt calm and peaceful? (d) have you felt downhearted and depressed? and (e) have you been happy? Each of the five questions has five response categories that are scored from 1 to 5 , where $1=$ all of the time, $2=$ most of the time, $3=$ some of the time, $4=$ a little of the time, and $5=$ none of the time. The scoring of questions (c) and (e) is reversed so that lower scores indicate worse mental health status for each question and the scores for each item were summed to give a range of scale scores from 5 to 25 . The response scores were then transformed to a discrete scale of 0 to 100 , where 100 represents the best mental health. ${ }^{18}$

\section{Survey population for analysis}

We included respondents aged 18-74 years because the MHI-5 is less reliable in more elderly populations. ${ }^{25}$ Furthermore, the proportion of respondents with incomplete mental health and sociodemographic data increased substantially over the age of 75 years. The mental health score was fully completed by 88958 $(97.7 \%)$ of the 91088 respondents aged $18-74$ years.

\section{Individual- and household-level variables}

We selected variables available in the data-set that have been shown to be significantly associated with mental health status in previous research. ${ }^{26-28}$ The individual-level variables were age (in 10-year bands), gender, employment status (coded as employed, seeking work, student, retired, permanently sick or disabled, home carer), and highest educational qualification (degree, other, none). The household-level variables were the National Statistics Socio-Economic Classification (NS-SEC) three-category variable for the head of household (defined as the person with the highest income), coded as professional/ managerial, intermediate, routine occupations, never worked/ long-term unemployed, ${ }^{29}$ and housing tenure (owner occupier, social and private tenant).

\section{Calculation of neighbourhood income inequality and deprivation}

We used validated gross household income estimates for 2001 used in previous research to estimate the neighbourhood income measures. ${ }^{10}$ The income data-set contains the percentage of

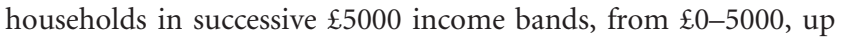
to $£ 95000-100000$, with a final band of $£ 100000$ and over, for each 1991 census enumeration district. Using a standard geographical look-up table we aggregated the smaller-level enumeration district data into the LSOA to merge to the survey data-set for analysis.

We estimated neighbourhood income inequality using the Gini coefficient, ${ }^{30}$ the most commonly used measure of income inequality. ${ }^{31}$ We calculated the score for each neighbourhood and unitary authority using data from the income data-set using this well-described method. ${ }^{30}$ The Gini coefficient can take values from zero, representing perfect equality, to one, representing maximal income inequality where one individual possesses all the wealth. We estimated the neighbourhood income deprivation variable as the per cent of households in each LSOA with a gross household income of less than $£ 10000$ per annum. This was the closest equivalent to the UK definition of poverty of $60 \%$ of median national household income. ${ }^{32}$

We assigned each LSOA into one of five ordinal categories for both income inequality and income deprivation separately, based on quintiles of each variable. To assess the interaction effect of the two income variables we derived a four-category variable where each LSOA was assigned to one of four groups based on cut-points at the median of the distributions: (a) low-income inequality and low deprivation, (b) high-income inequality and low deprivation, (c) low-income inequality and high deprivation, and (d) highincome inequality and high deprivation. With only 22 unitary authorities we dichotomised the income inequality variable at this level as 'high' and 'low', with the cut-point at the median of the distribution.

\section{Statistical analysis}

First, we assessed the ecological correlation between neighbourhood income inequality and income deprivation in a scatter plot. Second, we derived descriptive statistics for the associations between the MHI-5 score and both the neighbourhood income variables and the individual and household covariates. Third, the MHI-5 was modelled as the dependent variable in a four-level normal-response multilevel model with individuals at level one nested within households, within LSOAs, within unitary authorities. Although the distribution of MHI-5 scores is negatively skewed, we have shown the robustness of the scale to the standard regression assumptions of normality. ${ }^{10,33}$

The modelling strategy started with the 'null' four-level variance components model of random intercepts. Here the variation in the mental health score was modelled by random intercept terms for households, LSOAs and unitary authorities, and a random error term for individuals. In model 1, the LSOA income inequality variable was entered into the null model to obtain the unadjusted estimates. We then adjusted for income deprivation in model 2.

Individual- and household-level confounding variables were then entered to model 3 . The categorical variables were modelled so that the reference categories were age group 18-24 years, male, NS-SEC professional/managerial, employed, degree and owner occupier. We modelled missing data for each categorical variable as a dummy term to avoid the loss of data and to permit direct comparison of each model using the deviance statistic.

In model 4 we assessed the association between mental health and the pairs of neighbourhood income inequality and deprivation, with the pair of low inequality and low deprivation as the reference category. In model 5 we included the unitary authority term for high- and low-income inequality (reference category). Finally, we investigated whether the associations between mental health, neighbourhood income inequality and income deprivation varied between unitary authorities by including the cross-level interaction between the neighbourhood pairs and the unitary authority income inequality variable.

The models were fitted in MLwiN software version 2.5 on Windows. ${ }^{34}$ Successive model fitting was assessed by change in the deviance statistic. The data were analysed using weights calculated to correct for unequal household selection probabilities and for survey non-response. ${ }^{16}$ The validity of the final models was assessed using standard diagnostic plots of residuals at each level in the model. In order to check our main results using logistic regression, which avoids distributional assumptions about 
the MHI-5, we also defined a cut-point to define a 'case' of common mental disorder on the MHI-5 scale. Based on our previous work using the prevalence matching method with the GHQ-12, the cut-point on the MHI-5 scale to define a case of common mental disorders was $\leqslant 60$, equivalent to a score of $\leqslant 17$ on the untransformed scale. ${ }^{22}$ Using this cut-point we then modelled the binary outcome of case/non-case of common mental disorder in a logistic multilevel model.

\section{Results}

The mean mental health score for the 88958 respondents was 73.5 (s.d. =19.4). A total of $22717(25.5 \%)$ of respondents were categorised as 'cases' of common mental disorders. Poorer mental health was significantly associated with female gender, the mid-life age groups, and lower socioeconomic and educational status (Table 1).

Survey responses were obtained from individuals living in all 1896 LSOAs (mean 47 responses, range 5-183) and from all 22 unitary authorities (mean 4043, range 3466-6543). At LSOA level, the mean mental health score varied between 47.5 and 89.5 , and at unitary authority level, the mean mental health score varied between 68.9 and 76.5 .
Gini coefficients could be calculated for 1887 of the 1896 LSOAs. Nine were missing because not every enumeration district could be allocated to an LSOA due to overlapping boundaries. There were 335 respondents $(0.4 \%)$ who did not have an LSOA Gini coefficient. Their characteristics did not differ from the respondents with an associated Gini coefficient and so were excluded from the analysis, leaving the final sample for analysis of 88623 . The range of Gini coefficients was $0.27-0.58$ for LSOAs (mean 0.40 , s.d. $=0.035$ ) and $0.39-0.45$ for unitary authorities (mean 0.41 , s.d. $=0.018$ ). The mean percentage of households below the poverty line (income deprivation) for LSOAs was $19.3 \%$ (range 2-47). Figure 1 shows the relationship between the two income measures at LSOA-level; the scatter of income inequality is greater at low levels of deprivation compared with higher levels of deprivation.

Table 2 shows that the relationship between income inequality and mental health is non-linear with the best mental health in neighbourhoods with the highest income inequality, in contrast to income deprivation where the relationship is plausibly linear with higher deprivation associated with worse mental health. Neighbourhoods categorised as high-income inequality and low deprivation had better mental health than neighbourhoods with high-income inequality and high deprivation. The effect of deprivation was substantially greater than the effect of income inequality.

\begin{tabular}{|c|c|c|c|c|c|}
\hline Variable and parameter & $\begin{array}{l}\text { Respondents, } n \text { (\%) } \\
\quad(n=88958)\end{array}$ & $\begin{array}{l}\text { Mental health } \\
\text { score, mean }\end{array}$ & s.d. & $n(\%)$ of cases & $95 \% \mathrm{Cl}$ \\
\hline \multicolumn{6}{|l|}{ Age group } \\
\hline $18-24$ & $9096(10.2)$ & 74.9 & 18.2 & $2090(23.0)$ & 22.2-23.9 \\
\hline $25-34$ & $12603(14.2)$ & 73.6 & 18.6 & $3068(24.3)$ & 23.6-25.1 \\
\hline $35-44$ & $17416(19.6)$ & 72.9 & 19.2 & $4444(25.5)$ & $24.9-26.2$ \\
\hline $45-54$ & 17415 (19.6) & 72.1 & 20.2 & $4741(27.2)$ & $26.6-27.9$ \\
\hline $55-64$ & $18417(20.7)$ & 73.2 & 20.0 & $4947(26.9)$ & $26.2-27.5$ \\
\hline $65-74$ & $14011(15.8)$ & 75.1 & 19.2 & $3427(24.5)$ & $23.8-25.2$ \\
\hline \multicolumn{6}{|l|}{ Gender } \\
\hline Male & $41432(46.6)$ & 75.7 & 18.8 & 9062 (21.9) & $21.7-22.5$ \\
\hline Female & $47526(53.4)$ & 71.5 & 19.8 & $13655(28.7)$ & $28.3-29.1$ \\
\hline \multicolumn{6}{|l|}{ Social class (NS-SEC3) } \\
\hline Professional/managerial & $30849(34.7)$ & 76.4 & 17.2 & $5875(19.0)$ & $18.6-19.5$ \\
\hline Intermediate & $16883(19.0)$ & 74.8 & 18.8 & $3892(23.1)$ & $22.4-23.7$ \\
\hline Routine & $36043(40.5)$ & 70.9 & 20.9 & 11270 (31.3) & $30.8-31.8$ \\
\hline Never worked/long-term unemployed & $1801(2.0)$ & 62.5 & 23.7 & $855(47.5)$ & $45.2-49.8$ \\
\hline Missing & $3382(3.8)$ & 73.4 & 18.3 & $825(24.4)$ & 23.0-25.9 \\
\hline \multicolumn{6}{|l|}{ Employment status } \\
\hline Employed & $48647(54.7)$ & 76.9 & 16.2 & $8877(18.2)$ & 17.9-18.6 \\
\hline Seeking work & 1659 (1.9) & 69.7 & 20.8 & $541(32.6)$ & $30.4-34.9$ \\
\hline Home or carer & $7940(8.9)$ & 70.8 & 19.7 & $2462(31.0)$ & $30.0-32.0$ \\
\hline Student & $3163(3.6)$ & 74.8 & 17.0 & $696(22.0)$ & $20.6-23.5$ \\
\hline Permanently sick or disabled & $7653(8.6)$ & 51.8 & 23.7 & $5071(66.3)$ & $66.0-68.1$ \\
\hline Retired & $15522(17.4)$ & 75.8 & 18.7 & $3572(23.0)$ & $22.4-23.7$ \\
\hline Other & $2299(2.6)$ & 71.2 & 20.5 & $725(31.5)$ & $29.7-33.5$ \\
\hline Missing & 2075 (2.3) & 68.5 & 22.0 & 773 (37.3) & $35.2-39.4$ \\
\hline \multicolumn{6}{|l|}{ Highest educational qualification } \\
\hline Degree & $14632(16.4)$ & 76.9 & 16.2 & $2482(17.0)$ & $16.4-17.6$ \\
\hline Other & $48034(54.0)$ & 74.8 & 18.5 & $10888(22.7)$ & 22.3-23.0 \\
\hline None & 21809 (24.5) & 69.2 & 21.9 & 7717 (35.4) & $34.8-36.0$ \\
\hline Missing & $4483(5.0)$ & 69.0 & 21.6 & $1630(36.4)$ & $35.0-37.8$ \\
\hline \multicolumn{6}{|l|}{ Housing tenure } \\
\hline Owner occupier & 69015 (77.6) & 75.3 & 18.1 & 15126 (21.9) & $21.6-22.2$ \\
\hline Social renting & 11936 (13.4) & 64.3 & 23.2 & $5259(44.1)$ & $43.2-45.0$ \\
\hline Private renting & $7633(8.6)$ & 71.1 & 20.1 & $2246(29.4)$ & $28.4-30.5$ \\
\hline Missing & $374(0.4)$ & 75.4 & 17.3 & $86(23.0)$ & $19.0-27.5$ \\
\hline
\end{tabular}




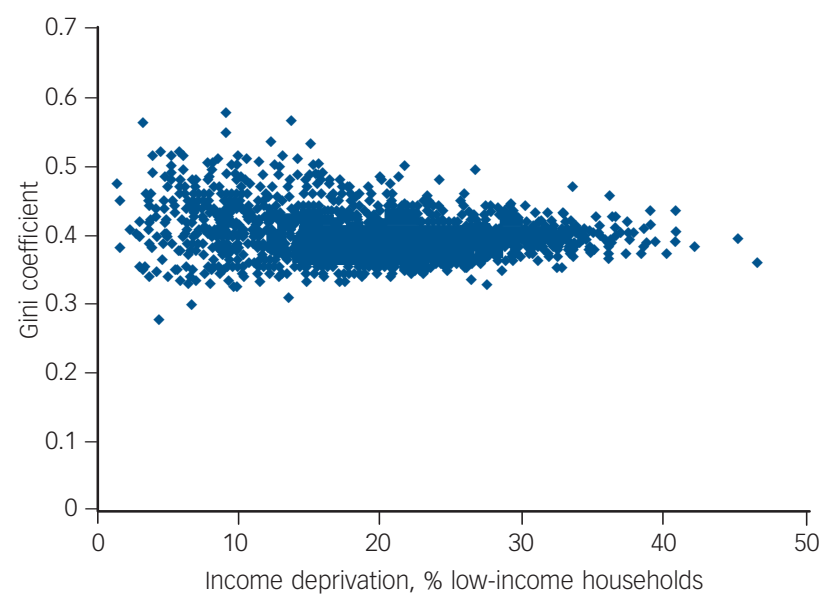

Fig. 1 Relationship between neighbourhood income deprivation and income inequality at lower super output areas (LSOA) level. ${ }^{2}$

a. Income deprivation measured at LSOA-level as the percentage of households earning less than $f 10000$ per annum, equivalent to the UK definition of poverty of less than $60 \%$ of median income. Income inequality measured using the LSOA Gini coefficient.

\section{Null model}

The random effects variance estimates are shown in Table 3 . The null model was specified as 88623 respondents with a mental health score, living within 50587 households, each nested within one of the 1887 LSOAs with a Gini coefficient. In the null model, the mean mental health score was 73.1 (s.e. $=0.51$ ). The majority of the variance $(65 \%)$ occurred at the individual level, with $32 \%$ at the household level, $2.4 \%$ at LSOA level and $1.4 \%$ at unitary authority level.

\section{Associations between mental health, income inequality and income deprivation}

In model 1, the lowest quintiles of income inequality were significantly associated with worse mental health and the quintile of highest income inequality was positively associated with better mental health (Table 3). The magnitude of the positive effect in the quintile of highest income inequality was more than twice the negative effect associated with the quintile of least income inequality.

After adjusting for income deprivation in model 2, the two highest quintiles of income inequality remained significantly associated with better mental health. We found a gradient of worsening mental health with increasing income deprivation. In model 3, after adjusting for individual and household covariates, this gradient remained but was attenuated. Only the highest quintile of income inequality remained significantly associated with better mental health.

Compared with neighbourhoods categorised as low-income inequality and low-income deprivation, model 4 shows that living in high-inequality and low-deprivation neighbourhoods was associated with better mental health, although the estimate was of borderline significance $(P=0.036)$ and the overall fit of the model was not significantly better than the previous model 3 (difference in the deviance 4.6, $P=0.2$ ). In neighbourhoods of high deprivation the degree of inequality had little effect.

In models 3 and 4, the addition of the neighbourhood- and individual-level parameters substantially reduced the random effects variance at both LSOA and unitary authority levels. However, the household level was little changed, accounting for $30.3 \%$ of the unexplained variance in the mental health score.

\section{Associations between unitary and neighbourhood income inequality}

In model 5, the estimate for the unitary authority income inequality variable suggested that living in regions of high inequality was associated with poorer mental health $(P=0.012)$. The cross-level interaction was not significant (estimates not shown), suggesting that this unitary authority effect did not vary with the level of inequality and deprivation at the smaller neighbourhood level.

\section{Model checking}

Due to the negative skew of the MHI-5 scale scores, the individuallevel residuals were, as expected, negatively skewed. The LSOA residuals were normally distributed in each model. No spatial

\begin{tabular}{|c|c|c|c|c|c|}
\hline & $\begin{array}{l}\text { Respondents, } n \text { (\%) } \\
\quad(n=88623)\end{array}$ & $\begin{array}{l}\text { Mental health } \\
\text { score, mean }\end{array}$ & $95 \% \mathrm{Cl}$ & $n(\%)$ of cases & $95 \% \mathrm{Cl}$ \\
\hline \multicolumn{6}{|l|}{ Quintiles of income inequality } \\
\hline Lowest & $18851(21.3)$ & 73.5 & $73.2-73.7$ & $4898(26.0)$ & $25.4-26.6$ \\
\hline Low & $17989(20.3)$ & 72.6 & $72.3-72.9$ & $4942(27.5)$ & $26.8-28.1$ \\
\hline Middle & $17914(20.2)$ & 72.6 & $72.3-72.9$ & $4861(27.1)$ & $26.5-27.8$ \\
\hline High & $17181(19.4)$ & 73.2 & $72.9-73.4$ & $4488(26.1)$ & $25.5-26.8$ \\
\hline Highest & $16688(18.8)$ & 75.6 & $75.3-75.8$ & $3450(20.7)$ & $20.1-21.3$ \\
\hline \multicolumn{6}{|l|}{ Quintiles of income deprivation } \\
\hline Lowest & $17574(19.8)$ & 76.3 & $76.1-76.6$ & $3469(19.7)$ & $19.2-20.3$ \\
\hline Low & $18614(21.0)$ & 75.4 & $75.1-75.6$ & 3975 (21.4) & $20.8-22.0$ \\
\hline Middle & $18732(21.1)$ & 73.9 & $73.7-74.2$ & $4630(24.7)$ & $24.1-25.3$ \\
\hline High & $17994(20.3)$ & 71.8 & $71.5-72.1$ & $5196(28.9)$ & $28.2-29.5$ \\
\hline Highest & $15709(17.7)$ & 69.3 & $68.9-69.6$ & $5369(34.2)$ & $33.4-34.9$ \\
\hline \multicolumn{6}{|c|}{ Income inequality and income deprivation pairs ${ }^{b}$} \\
\hline Low inequality + low deprivation & $21541(24.3)$ & 74.8 & $74.5-75.0$ & $4975(23.1)$ & $22.5-23.7$ \\
\hline High inequality + low deprivation & $23818(26.9)$ & 76.2 & $76.0-76.4$ & $4700(19.7)$ & $19.2-20.2$ \\
\hline High inequality + high deprivation & $24090(27.2)$ & 71.2 & 70.9-71.4 & $7345(30.5)$ & 29.9-31.1 \\
\hline Low inequality + high deprivation & $19174(21.6)$ & 71.5 & $71.2-71.8$ & $5619(29.3)$ & $28.7-30.0$ \\
\hline
\end{tabular}




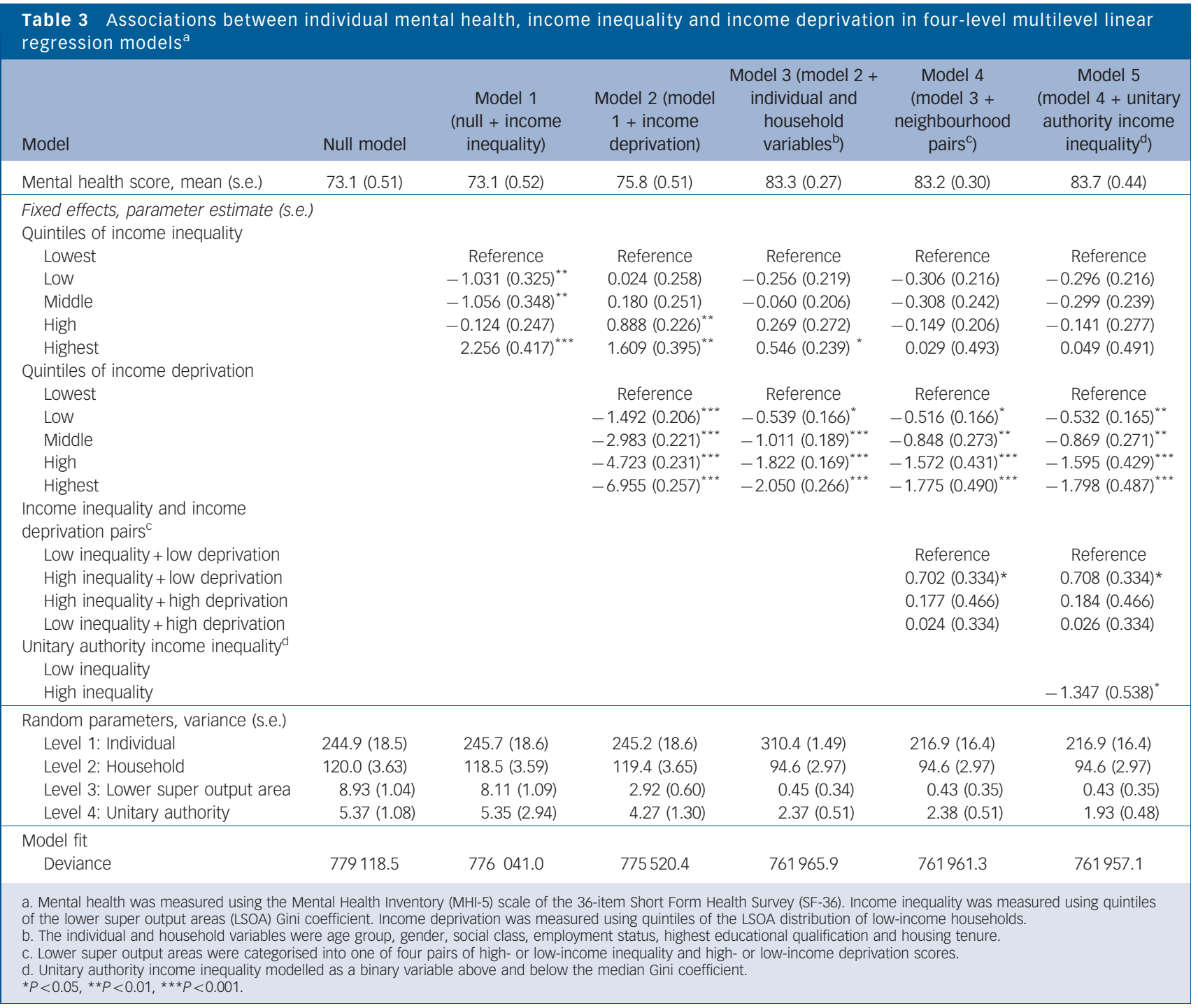

pattern in these residuals was found and there was no correlation between the residuals and the income inequality variable. Although the largest proportion of missing data was small (5\%), we also performed a complete case analysis, omitting the dummy variables for 'missing', and found no difference in the pattern of results.

\section{Logistic models of case $v$. non-case of common mental disorders}

The odds ratios (ORs) in the logistic models showed a similar pattern of significance as in the corresponding normal models (Table 4). The OR for a case of common mental disorders for living in neighbourhoods of high-income inequality and low-income deprivation was 0.92 (95\% CI 0.88-0.97) and the ORs for a case of common mental disorders for living in high-income inequality unitary authorities was 1.13 (95\% CI 1.04-1.22). With a population case prevalence of $25.5 \%$ these correspond to relative risks of approximately 0.94 (95\% CI $0.91-0.97$ ) for high-inequality/ low-deprivation neighbourhoods and 1.09 (95\% CI 1.03-1.15) for unitary authorities with high-income inequality.

\section{Discussion}

\section{Main findings}

We found that living in neighbourhoods with the highest levels of income inequality was significantly associated with better mental health. This association was attenuated but remained statistically significant after adjusting for neighbourhood income deprivation and individual and household risk factors. The magnitude of the positive association between mental health and neighbourhood income inequality was substantially smaller, by a factor of four, than the negative association between mental health and neighbourhood income deprivation.

Our results suggest that this association of better mental health with income inequality operated only in low-deprivation neighbourhoods. Mental health was better for people living in neighbourhoods categorised as high inequality and low deprivation, but income inequality had no significant effect in high-deprivation neighbourhoods. At the larger regional level, with a mean population of 135000 , higher-income inequality was associated with significantly poorer mental health, in contrast to the findings at the smaller neighbourhood level.

Overall we found evidence to support the hypothesis that living in neighbourhoods characterised as being in poverty compared with an external national standard was more important in determining mental health status than within-neighbourhood income differences. ${ }^{2,4}$ The Gini coefficient is insensitive to the shape of the income distribution within geographical areas, so that a high Gini coefficient could result from either a high proportion of people with very low incomes or very high incomes. ${ }^{30,31}$ Thus, in our study it is possible that low-deprivation neighbourhoods 


\begin{tabular}{|c|c|c|c|c|c|}
\hline & \multicolumn{5}{|c|}{ Odds ratios $(95 \% \mathrm{Cl})$} \\
\hline & $\begin{array}{c}\text { Model } 1 \\
\text { (null + income } \\
\text { inequality) }\end{array}$ & $\begin{array}{c}\text { Model } 2 \\
\text { (null + income } \\
\text { deprivation + } \\
\text { income inequality) }\end{array}$ & $\begin{array}{c}\text { Model } 3 \text { (model } \\
2+\text { individual and } \\
\text { household } \\
\text { variables }^{b} \text { ) }\end{array}$ & $\begin{array}{c}\text { Model } 4 \\
\text { (model } 3+ \\
\text { neighbourhood } \\
\text { pairs }^{\mathrm{c}} \text { ) }\end{array}$ & $\begin{array}{l}\text { Model } 5 \text { (model } \\
4+\text { unitary } \\
\text { authority income } \\
\text { inequality) }\end{array}$ \\
\hline \multicolumn{6}{|l|}{ Quintiles of income inequality } \\
\hline Lowest & Reference & Reference & Reference & Reference & Reference \\
\hline Low & $1.09(1.06-1.13)$ & $0.98(0.95-1.01)$ & $1.02(0.99-1.05)$ & $1.02(0.99-1.05)$ & $1.02(0.99-1.05)$ \\
\hline Middle & $1.06(1.02-0.09)$ & $0.94(0.91-0.97)$ & $0.98(0.95-1.01)$ & $1.01(0.97-1.04)$ & $1.00(0.97-1.04)$ \\
\hline High & $0.99(0.96-1.03)$ & $0.89(0.86-0.92)$ & $0.95(0.92-0.98)$ & $1.00(0.95-1.05)$ & $1.00(0.95-1.05)$ \\
\hline Highest & $0.74(0.71-0.77)$ & $0.79(0.77-0.82)$ & $0.90(0.87-0.92)$ & $0.95(0.90-1.00)$ & $0.95(0.90-1.00)$ \\
\hline \multicolumn{6}{|l|}{ Quintiles of income deprivation } \\
\hline Lowest & & Reference & Reference & Reference & Reference \\
\hline Low & & $1.15(1.11-1.19)$ & $1.03(1.00-1.06)$ & $1.03(1.00-1.06)$ & $1.03(1.00-1.06)$ \\
\hline Middle & & $1.37(1.32-1.41)$ & $1.11(1.07-1.14)$ & $1.09(1.05-1.13)$ & $1.09(1.05-1.13)$ \\
\hline High & & $1.63(1.57-1.68)$ & $1.22(1.18-1.26)$ & $1.18(1.12-1.24)$ & $1.18(1.12-1.25)$ \\
\hline Highest & & $1.98(1.92-2.05)$ & $1.24(1.19-1.28)$ & $1.20(1.14-1.26)$ & $1.20(1.14-1.26)$ \\
\hline \multicolumn{6}{|c|}{ Income inequality and income deprivation pairs ${ }^{c}$} \\
\hline Low inequality + low deprivation & & & & Reference & Reference \\
\hline High inequality + low deprivation & & & & $0.92(0.88-0.97)$ & $0.92(0.88-0.97)$ \\
\hline High inequality + high deprivation & & & & $0.98(0.92-1.04)$ & $0.98(0.92-1.04)$ \\
\hline Low inequality + high deprivation & & & & $1.00(0.96-1.04)$ & $1.00(0.96-1.04)$ \\
\hline \multicolumn{6}{|l|}{ Unitary authority income inequality $^{d}$} \\
\hline Low inequality & & & & & Reference \\
\hline High inequality & & & & & $1.13(1.04-1.22)$ \\
\hline
\end{tabular}

have the highest levels of inequality due to the positive skew of the income distribution, in contrast to high-deprivation neighbourhoods in which absolute levels of income are lower with a smaller range and less variation.

\section{Possible mechanisms linking income inequality and mental health}

Three mechanisms have been proposed as possible explanations for associations between income inequality and mental health, reviewed recently by Layte. ${ }^{1}$ The first, the social capital hypothesis, argues that higher levels of income inequality lead to lower levels of social capital, which in turn lead to lower levels of health. The second, the status anxiety hypothesis, suggests that a stress response to the status anxiety that results from the perception of lower social status leads to poorer health. Third, the neomaterialist hypothesis, holds that income inequality leads to differential investment and reduced development of public infrastructure within a society, and this leads to poor health. Evidence for and against these three main hypotheses is mixed and largely inconclusive. ${ }^{1}$ It seems unlikely that the neo-materialist hypothesis could operate at small-area, neighbourhood level, since differential investment, such as local area regeneration schemes, operates between, rather than within, small neighbourhood areas. It is more likely that the status anxiety hypothesis, operating through 'invidious comparisons that increase people's stress, ${ }^{\text {, }}$ could manifest within low-deprivation, but unequal, neighbourhoods, as well as within regions and countries. Also more plausible at neighbourhood level is the social capital hypothesis, since we have previously found neighbourhood social cohesion to modify the adverse effect of neighbourhood income deprivation on poor mental health. ${ }^{10}$ If low deprivation neighbourhoods also tended to have higher levels of social capital, this hypothesis could possibly explain why income inequality was associated with better mental health in these neighbourhoods.

\section{Comparison with previous literature}

Our findings are in contrast to the only previous study at neighbourhood level, which found no association between mental health, measured using the World Health Organization Quality of Life (WHOQOL-BREF) measure, and neighbourhood income inequality and socioeconomic deprivation. ${ }^{9}$ However, this was a small study from the city of Maastricht in The Netherlands, analysing data on only 1082 participants aged between 35 and 45 years resident within a small number of neighbourhoods $(n=36)$ of population size ranging between 300 and 8500 . The study used two locally derived non-standard measures of income inequality based on the proportion of high and low incomes and house prices, and a composite index of socioeconomic deprivation. No association was found between mental health and either of the measures.

A British study of 8191 adults measured income inequality from survey responses on income levels using the Gini coefficient at regional level $(n=18)$. Individuals with the highest incomes were found to be more likely to have common mental disorders when living in regions of higher-income inequality. However, no association was found for median regional income and data were not available for smaller geographical areas. ${ }^{8}$ In this study, the mean population size of the regions was approximately 3 million, which is substantially higher than the mean neighbourhood population (1500) or unitary authority (150000) in our study.

Three US studies also measured income inequality in substantially larger geographical areas than in our study. The first compared psychiatric disorders assessed using the Composite International Diagnostic Interview in 9585 adults within 60 US 
economic areas ${ }^{5}$ and the second study outcome was depression assessed using the Center for Epidemiologic Studies instrument in 4817 US adults within counties. ${ }^{6}$ Both found no significant associations with income inequality. The third study, a postdisaster study of 1355 adults resident within the 59 large-scale community districts of New York City 6 months after 11 September 2001, measured income inequality using the Gini coefficient derived from US census data. The outcome measure was depression measured using the National Women's Study depression module, which is consistent with DSM-IV criteria. The study oversampled residents living close to the World Trade Center site and found that income inequality was associated with depression among participants with low individual income. ${ }^{7}$

\section{Strengths and limitations of the study}

The Welsh Health Survey has the strength of a large sampling fraction and high response rate resulting in a representative data-set of nearly 90000 adults. This equates to around 1 in 25 of a socially diverse population living in a geographically defined area, with detailed exposure data linked to the 2001 census LSOA of residence. We were able to estimate a standard measure of income inequality and deprivation for 1887 LSOAs at this smallarea level and match these to the survey data to facilitate a multilevel analysis at a smaller spatial scale and with many more neighbourhoods than previously reported. ${ }^{9}$ We have used the administrative census LSOA to represent the neighbourhood in this study and cannot assume that the LSOA is a good measure. However, the general problem of using non-homogeneous areas that result from the use of administrative boundaries is a tendency to lead to conservative estimates. ${ }^{35,36}$ Therefore it is unlikely that our results overestimated the associations between common mental disorders and the neighbourhood income measures. Because the primary sampling unit for the data-set was the household, we were able to include the household level in the multilevel analysis. This has been shown in previous research to be important in the analysis of common mental disorders. ${ }^{37,38}$ We found a notably larger household variance (approximately $30 \%)$ than previously reported, suggesting substantial withinhousehold similarity in mental health response to neighbourhood income influences.

The main limitations of the study are the cross-sectional design, which removes the possibility of causal inference, and likelihood of bias. Non-response bias is always a possibility but successive surveys had a consistently good overall response to the interviewer-led method, from $74 \%$ of sampled households and $85 \%$ of individuals within responding households in 2003/04 ${ }^{16}$ to $79 \%$ and $83 \%$ respectively in $2010 .{ }^{39}$ Lower response rates from some population subgroups are inevitable and can lead to bias in either direction if the relationships between the variables are substantially different in those subgroups from the rest of the population. The measure of mental health used was based on the survey responses to the MHI- 5 scale, which were not validated in a clinical interview. One statistical property of the MHI-5 is that the distribution of responses is significantly negatively skewed and thus may have violated the assumptions for linear regression. However, we found very similar results from modelling the scale as a binary variable of 'case' and 'non-case' of common mental disorders, which suggests that the normal response models were robust to departures from normality. We defined a case of common mental disorders on the MHI-5 based on our previous research, which compared MHI-5 with GHQ-12 scores in the British Household Panel Survey. ${ }^{22}$ Although there is potential for misclassification of 'cases', the resulting bias is most likely to be non-differential and therefore to the null.
We were not able to independently validate the income dataset, although the range of Gini coefficients was plausible in comparison with previous research and consistent with a 'threshold' effect of income inequality on health at Gini coefficients above $0.3 .^{31}$ A particular limitation of the income data-set was that we could not use it to contrast different measures of income inequality since the Gini coefficient and, for instance, the Robin Hood index ${ }^{30}$ will have identical quintiles because the income data-set is available in $\mathfrak{E 5 0 0 0}$ bands rather than as continuous values. A second limitation is that the income dataset for these small-areas only provides gross household income and so the differences between neighbourhoods in net household income are likely to be smaller than for gross income.

The income deprivation variable based on the percentage of households in poverty was highly correlated with the Welsh Index of Multiple Deprivation Income Domain ${ }^{40}$ (Spearman's $r=0.82$, $n=1887, P<0.001$ ), suggesting a high degree of linear association between these two measures of income deprivation. Although the data-set included data on a wide range of confounders that are risk factors for mental health status, no data were available on individual income. Therefore we were unable to investigate the effect of individual income or possible interactions with the neighbourhood income measures in this study.

\section{Implications}

Our findings suggest that income inequality at neighbourhood level is less important as a risk factor for common mental disorders than income deprivation. The effect of income inequality starts to operate at the larger regional level. Policies to reduce the prevalence of common mental disorders should focus on the social determinants of mental health by reducing the burden of small-area socioeconomic deprivation.

\section{David Fone, MBBS, MD, Giles Greene, BSc, PhD, Daniel Farewell, MMath, PhD, Institute of Primary Care \& Public Health, School of Medicine, Cardiff University; James White, BSC, MSC, PhD, Centre for the Development and Evaluation of Complex Public Health Interventions, School of Medicine, Cardiff University; Mark Kelly, BSC, MSc, PhD, Institute for Translation, Innovation, Methodology and Engagement, School of Medicine, Cardiff University; Frank Dunstan, MA, DPhil, Institute of Primary Care \& Public Health, School of Medicine, Cardiff University, UK \\ Correspondence: David Fone, MBBS, MD, Institute of Primary Care \& Public Health, School of Medicine, Cardiff University, Heath Park, Cardiff CF14 4YS, UK. Email: foned@cf.ac.uk \\ First received 8 Jun 2012, final revision 6 Nov 2012, accepted 8 Jan 2013}

\section{Funding}

This study was partly funded by the Office of the Chief Social Research Officer (OCSRO), Welsh Assembly Government as part of the 'National Surveys Secondary Analysis Programme'. The work was undertaken with the support of The Centre for the Development and Evaluation of Complex Interventions for Public Health Improvement (DECIPHer), a UKCRC Public Health Research: Centre of Excellence. Funding from the British Heart Foundation, Cancer Research UK, Economic and Social Research council (RES-590-28-0005), Medical Research Council, the Welsh Assembly Government and the Wellcome Trust (WTO87640MA), under the auspices of the UK Clinical Research Collaboration, is gratefully acknowledged.

\section{References}

1 Layte R. The association between income inequality and mental health: testing status anxiety, social capital, and neo-materialist explanations. Eur Sociol Rev 2012; 28: 498-511.

2 Wilkinson RG, Pickett KE. Income inequality and population health: a review and explanation of the evidence. Soc Sci Med 2006; 62: 1768-84.

3 Wilkinson RG, Pickett KE. The problems of relative deprivation: why some societies do better than others. Soc Sci Med 2007; 65: 1965-78.

4 Pickett KE, Wilkinson RG. Inequality: an underacknowledged source of mental illness and distress. Br J Psychiatry 2010; 197: 426-8. 
5 Sturm R, Gresenz CR. Relations of income inequality and family income to chronic medical conditions and mental health disorders: national survey. BM. 2002; 324: 20-3.

6 Zimmerman FJ, Bell JF. Income inequality and physical and mental health: testing associations consistent with proposed causal pathways. J Epidemiol Community Health 2006; 60: 513-21.

7 Ahern J, Galea S. Social context and depression after a disaster: the role of income inequality. J Epidemiol Community Health 2006; 60: 766-70.

8 Weich S, Lewis G, Jenkins SP. Income inequality and the prevalence of common mental disorders in Britain. Br J Psychiatry 2001; 178: 222-7.

9 Drukker M, Feron FJM, Van Os J. Income inequality at neighbourhood level and quality of life. Soc Psychiatry Psychiatr Epidemiol 2004; 39: 457-63.

10 Fone D, Dunstan F, Lloyd K, Williams G, Watkins J, Palmer S. Does social cohesion modify the association between area income deprivation and mental health? A multilevel analysis. Int J Epidemiol 2007: 36: 338-45.

11 Adams RJ, Howard N, Tucker G, Appleton S, Taylor AW, Chittleborough C, et al. Effects of area deprivation on health risks and outcomes: a multilevel, cross-sectional, Australian population study. Int J Public Health 2009; 54: 183-92.

12 Piro $F$, Naess $O$, Claussen $B$. Area deprivation and its association with health in a cross-sectional study: are the results biased by recent migration? Int J Equity Health 2007: 6: 10.

13 Stafford M, Marmot M. Neighbourhood deprivation and health: does it affect us all equally? Int J Epidemiol 2003; 32: 357-66.

14 Skapinakis $P$, Lewis $G$, Araya R, Jones K, Williams G. Mental health inequalities in Wales, UK: multi-level investigation of the effect of area deprivation. Br J Psychiatry 2005; 186: 417-22.

15 Doyle-Francis M, Sadler K, Kingdon A, Roberts C, Walters L. Welsh Health Survey User Guide. National Centre for Social Research, Welsh Assembly Government, 2011.

16 McGee A, Jotangia D, Prescott A, Pickering K, Sproston K. Welsh Health Survey - Year One. Technical Report. National Centre for Social Research, 2005.

17 Office for National Statistics. Super Output Areas (SOAS). Office for Nationa Statistics, 2011.

18 Ware JE, Kosinski M, Dewey JE. How to Score Version Two of the SF-36 Health Survey. QualityMetric Incorporated, 2000.

19 Ware JE, Gandek B. Overview of the SF-36 health survey and the international quality of life assessment (IQOLA) project. J Clin Epidemiol 1998; 51: $903-12$

20 Berwick DM, Murphy JM, Goldman PA, Ware Jr JE, Barsky AJ, Weinstein MC. Performance of a five-item mental health screening test. Med Care 1991; 29 169-76.

21 McCabe CJ, Thomas KJ, Brazier JE, Coleman P. Measuring the mental health status of a population: a comparison of the GHQ-12 and the SF-36 (MHI-5) Br J Psychiatry 1996; 169: 516-21.

22 Kelly M, Dunstan F, Lloyd K, Fone D. Evaluating cutpoints for the MHI-5 and MCS using the GHQ-12: a comparison of five different methods. BMC Psychiatry 2008; 8: 10
23 Rumpf H-J, Meyer C, Hapke U, John U. Screening for mental health: validity of the MHI-5 using DSM-IV Axis I psychiatric disorders as gold standard Psychiatry Res 2001; 105: 243-53.

24 Cuijpers $\mathrm{P}$, Smits $\mathrm{N}$, Donker $\mathrm{T}$, ten Have $\mathrm{M}$, de Graaf R. Screening for mood and anxiety disorders with the five-item, the three-item, and the two-item Mental Health Inventory. Psychiatry Res 2009; 168: 250-5.

25 Hayes V, Morris J, Wolfe C, Morgan M. The SF-36 health survey questionnaire: is it suitable for use with older adults? Age Ageing 1995; 24: $120-5$.

26 Weich S. Prevention of the common mental disorders: a public health perspective. Psychol Med 1997; 27: 757-64

27 Lewis G, Bebbington P, Brugha T, Farrell M, Gill B, Jenkins R, et al. Socioeconomic status, standard of living, and neurotic disorder. Lancet 1998; 352: $605-9$.

28 Fryers $T$, Melzer $D$, Jenkins R. Social inequalities and the common mental disorders. Soc Psychiatry Psychiatr Epidemiol 2003; 38: 229-37.

29 office for National Statistics. Standard Occupational Classification 2010. Volume 3 The National Statistics Socio-economic Classification: (Rebased on the SOC2010) User Manual. Palgrave Macmillan, 2010.

30 De Maio FG. Income inequality measures. J Epidemiol Community Health 2007; 61: 849-52.

31 Kondo N, Sembajwe G, Kawachi I, Van Dam RM, Subramanian S, Yamagata Z. Income inequality, mortality, and self rated health: meta-analysis of multilevel studies. BMJ 2009; 339: b4471.

32 National Statistics, Department for Work and Pensions. Households Below Average Income: An Analysis of the Income Distribution 1994/95-2009/10. Department for Work and Pensions, 2011 (http://research.dwp.gov.uk/asd/ hbai/hbai2010/pdf_files/full_hbai11.pdf).

33 Fone DL, Dunstan FD. Mental health, places and people: a multilevel analysis of economic inactivity and social deprivation. Health Place 2006; 12: 332-44.

34 Rasbash J, Steele F, Browne W, Goldstein H. A User's Guide to M/wiN version 2.10. University of Bristol, Centre for Multilevel Modelling, 2009.

35 Blakely TA, Woodward AJ. Ecological effects in multi-level studies. J Epidemiol Community Health 2000; 54: 367-74.

36 Stafford M, Duke-Williams $\mathrm{O}$, Shelton N. Small area inequalities in health: are we underestimating them? SOC Sci Med 2008; 67: 891-9.

37 Weich S, Holt G, Twigg L, Jones K, Lewis G. Geographic variation in the prevalence of common mental disorders in Britain: a multilevel investigation. Am J Epidemiol 2003; 157: 730-7.

38 Weich S, Twigg L, Holt G, Lewis G, Jones $\mathrm{K}$. Contextual risk factors for the common mental disorders in Britain: a multilevel investigation of the effects of place. J Epidemiol Community Health 2003; 57: 616-21.

39 Sadler K, Doyle M, Hussey D, Stafford R. Welsh Health Survey 2010 Technical Report. National Centre for Social Research, 2011.

40 Local Government Data Unit - Wales. Welsh Index of Multiple Deprivation 2005. Summary Report. Welsh Government, 2005. 